\title{
MICROBACIA HIDROGRÁFICA DO RIACHO VAL PARAÍSO: ANÁLISE SOCIOECONÔMICA
}

\author{
J. D. DE S. BARROS ${ }^{1}$, L. H. G. CHAVES ${ }^{2}$ e S. A. R. FARIAS ${ }^{2}$ \\ ${ }^{1}$ Doutorando do Programa de Pós-Graduação em Recursos Naturais; Universidade Federal de Campina Grande - \\ UFCG. Bolsista do CNPq - Brasil \\ ${ }^{2}$ Departamento de Engenharia Agrícola, CTRN/UFCG, Av. Aprígio Veloso 882, 58429-900, Campina Grande-PB \\ deomarbarros@gmail.com - Ihgarofalo@hotmail.com - soahd.rached@gmail.com
}

Artigo submetido em maio/2014 e aceito em julho/2014

DOI: 10.15628/holos.2014.1579

\section{RESUMO}

Mensurar a deterioração socioeconômica de uma microbacia hidrográfica é um dos primeiros passos necessários para adotar medidas mitigadoras, com vista ao desenvolvimento sustentável local. Neste sentido, o presente trabalho teve por objetivo determinar as deteriorações socioeconômicas da microbacia hidrográfica do Riacho Val Paraiso - PB. A referida pesquisa foi realizada no período de 10 de maio de 2013 a 03 de julho de 2013, contendo uma amostra de 68 famílias. Foi elaborado um questionário socioeconômico, de acordo com a metodologia de Rocha (1997), e aplicado na forma de entrevistas em visitas feitas as comunidades rurais que fazem parte da microbacia supramencionada. Os resultados obtidos indicam que a região se encontra em elevado processo de deterioração socioeconômica, com mais de $50 \%$ da área comprometida.

PALAVRAS-CHAVE: deterioração socioeconômica, desenvolvimento sustentável, fator social, fator econômico, fator tecnológico

\section{WATERSHED OF RIACHO VAL PARAÍSO: SOCIOECONOMIC ANALYSIS}

\begin{abstract}
Measure the socioeconomic deterioration of a watershed is one of the first steps to adopt mitigation measures, with a view to sustainable local development. In this sense, the present study aimed to determine the deterioration of socio economic watershed of Riacho Val Paraíso - PB. That survey was conducted from May 10 2013 to 03 July 2013, containing a sample of 68 families.
\end{abstract}

A socioeconomic questionnaire was developed according to the methodology of Rocha (1997), and applied in the form of interviews with rural communities that are part of the watershed above. The results obtained indicate that the region is in a high socioeconomic deterioration process, over $50 \%$ of the affected area.

KEYWORDS: socioeconomic deterioration, sustainable development, social factors, economic factors, technological factors. 


\section{INTRODUÇÃO}

A compreensão da complexa relação entre sociedade e natureza vem se aprimorando especialmente a partir da década de 1990, tendo em vista esta complexidade torna-se indispensável à participação social na gestão da biodiversidade local e avaliação dos fatores socioeconômicos e culturais presentes no espaço no qual está inserido. Neste sentido, Alves et al. (2012), expõe que a bacia hidrográfica é um espaço favorável para se conhecer e avaliar os seus diversos componentes, processos e interações.

O estabelecimento da Política Nacional de Recursos Hídricos (Lei $n^{\circ} 9.433$ de 08 de janeiro de 1997) consolidou a bacia hidrográfica no cenário de gestão dos recursos naturais, tendo em vista o favorecimento da gestão integrada. Apresentando como uma de suas diretrizes a adequação da gestão dos recursos hídricos às diversidades físicas, bióticas, demográficas, econômicas, sociais e culturais (ABREU et al., 2011).

Neste sentido, a microbacia compõe o lócus de um programa integrado, cujas medidas e ações devem atender as necessidades das comunidades nela inseridas, para que ocorram melhorias na produtividade, da renda e do bem-estar; imprescindíveis ao desenvolvimento socioambiental local.

Conforme Rocha \& Kurtz (2001), o manejo integrado de bacias hidrográficas visa à recuperação ambiental das áreas degradadas, equilibrando os ecossistemas e buscando a sustentabilidade dos recursos naturais renováveis, por meio da elaboração e aplicação de diagnósticos quantitativos e qualitativos. Um diagnóstico socioeconômico busca soluções para resolver os problemas de qualidade de vida das pessoas que vivem nas sub-bacias hidrográficas. Neste sentido, o diagnóstico é efetivado com o objetivo de conhecer os problemas que afetam uma população, por meio de observações, questionamentos, análises e interpretação dos fatores que estão relacionados à qualidade de vida. De acordo com Franco et al. (2005) o diagnóstico socioeconômico tem por objetivo analisar a situação social, econômica e tecnológica da população residente na microbacia, no sentido de avaliar a deterioração socioeconômica. Com isso, é possível elaborar recomendações no sentido de elevar a qualidade e o nível de vida na bacia ou microbacia em estudo.

Assim, um diagnóstico do nível de deterioração socioeconômico na microbacia do Riacho Val Paraíso-PB, se faz imprescindível e oportuno, uma vez que não se tem conhecimento de qualquer trabalho que indique o retrato da problemática socioeconômica causada pelas práticas agropecuária na região. Diante do exposto, objetivou-se com este estudo determinar o grau de deterioração socioeconômica da microbacia hidrográfica Val Paraíso - PB.

\section{FUNDAMENTAÇÃO TEÓRICA}

O semiárido brasileiro apresentando características climáticas típicas, além de exibir ciclos de secas frequentes, é caracterizado por apresentar uma ampla variedade ambiental (solos, clima, vegetação e relevo) formando um ambiente diversificado e único. Na região, as atividades agropastoris são preponderantemente de cunho familiar (ARAUJO, 2010). 
De acordo com Silva et al. (2010), no Nordeste semiárido cerca de 90\% do número de estabelecimentos tem área inferior a 100 ha que somado a uma condição de apoio em termos de crédito e de assistência técnica, ainda bastante precária, resulta em um baixo desempenho da agropecuária da região.

A alta concentração de minifúndios revela a existência de grande concentração de trabalhadores e famílias rurais deles dependentes. Esta categoria de estabelecimento, pela própria característica e dimensões, não assegura uma renda suficiente que garanta um padrão social e econômico mais digno para as famílias.

Esta condição tem contribuído para o êxodo rural. Neste sentido, para evitar a migração da população rural se faz necessário o desenvolvimento de ações e de um conjunto de inovações técnicas, econômicas e sociais adaptadas às condições locais capazes de promover a valorização dos recursos produtivos em suas diversas combinações. Para que ocorra o desenvolvimento sustentável desta região se faz necessário a identificação das vocações econômicas locais que se traduzam na geração de emprego e renda (BARROS \& SILVA, 2010).

Sá et al. (2012), pesquisando a sustentabilidade dos sistemas de produção dos agricultores familiares em Nossa Senhora da Glória, semiárido sergipano, verificaram que os sistemas de produção apresentaram baixos índices sociais para a moradia e nível educacional; baixos índices ambientais, escassez de assistência técnica e financiamento e baixos índices econômicos. Resultados semelhantes foram encontrados por Sousa et al. (2008).

Contrário a este pensamento Camelo \& Cândido (2012) com o objetivo de identificar as potencialidades e as limitações dos agroecossistemas de abacaxi numa perspectiva de desenvolvimento sustentável em Touros-RN, verificaram que os agricultores consideram que o cultivo do abacaxi vem sendo responsável pelas transformações ocorridas na localidade onde residem; os agricultores desenvolveram uma autossuficiência econômica que garante uma melhor qualidade de vida e a sustentabilidade econômica de suas famílias no meio rural.

Apesar das dificuldades que passa a economia do semiárido, uma série de novas atividades começa a ser implementadas permitindo a estruturação de novos espaços econômicos. Diversos estudos têm mostrado o crescimento do número de experiências organizacionais e produtivas bem sucedidas desenvolvidas na organização familiar, que vêm superando a vulnerabilidade dos agroecossistemas diante das secas e constituindo alternativa econômica sustentável. Diversas atividades produtivas tradicionais a exemplo da pecuária de leite, ovinocultura, apicultura, fruticultura, entre outras, tem sido implantadas como alternativas as atividades agrícolas tradicionais. Estas atividades de base local se constituem atividade relevante na busca de alternativas para a crise socioeconômica e ambiental da região (SÁ et al., 2010).

Neste sentido, Reis \& Cândido (2012) investigando a sustentabilidade dos agroecossistemas intensivos de bananeira em I panguaçu - RN verificaram que quanto à produtividade e aos recursos naturais, o nível de sustentabilidade dos agroecossistemas configura um estado ótimo e um nível instável, respectivamente. Segundo Lira (2010) a adoção de um manejo sustentável do solo da caatinga é capaz de diversificar a produção, o que garante a sustentabilidade econômica e proporciona um melhor aproveitamento das unidades produtivas.

Diversos estudos têm mostrado o crescimento do número de experiências organizacionais e produtivas bem sucedidas desenvolvidas na organização familiar, que vêm superando a 
vulnerabilidade dos agroecossistemas diante das secas e constituindo alternativa econômica sustentável. Diversas atividades produtivas tradicionais a exemplo da pecuária de leite, ovinocultura, apicultura, fruticultura, entre outras, tem sido implementadas como alternativas as atividades agrícolas tradicionais. Estas atividades de base local se constituem atividade relevante na busca de alternativas para a crise da economia da região (SÁ et al. 2010).

Barreto (2010) verificou que a adoção de manejo agroecológico em unidades de produção familiar no Oeste Potiguar garantiu benefícios sociais às unidades produtivas familiares. Este manejo contribui fortemente para o incremento da receita nas unidades familiares estudadas, gerando impacto econômico positivo.

Embora as atividades agropecuárias representem relevância na composição da estrutura de renda da população rural, destaca-se a importância de outras atividades econômicas que permitem a exploração dos recursos naturais locais em sintonia com a valorização da natureza. Ou seja, faz-se necessário o desenvolvimento de atividades que promovam a imagem de uma determinada localidade através do desenvolvimento de bens primários de qualidade, artesanato tradicional, atividades culturais e de lazer, entre outras atividades (SÁ \& SOUZA, 2012).

Assim, atividades dessa natureza cuja implementação seja potencializada por meio de ações de organizações da sociedade civil podem contribuir para a construção de ações sustentáveis de convivência com o semiárido.

\section{METODOLOGIA}

3.1 Área de estudo da pesquisa

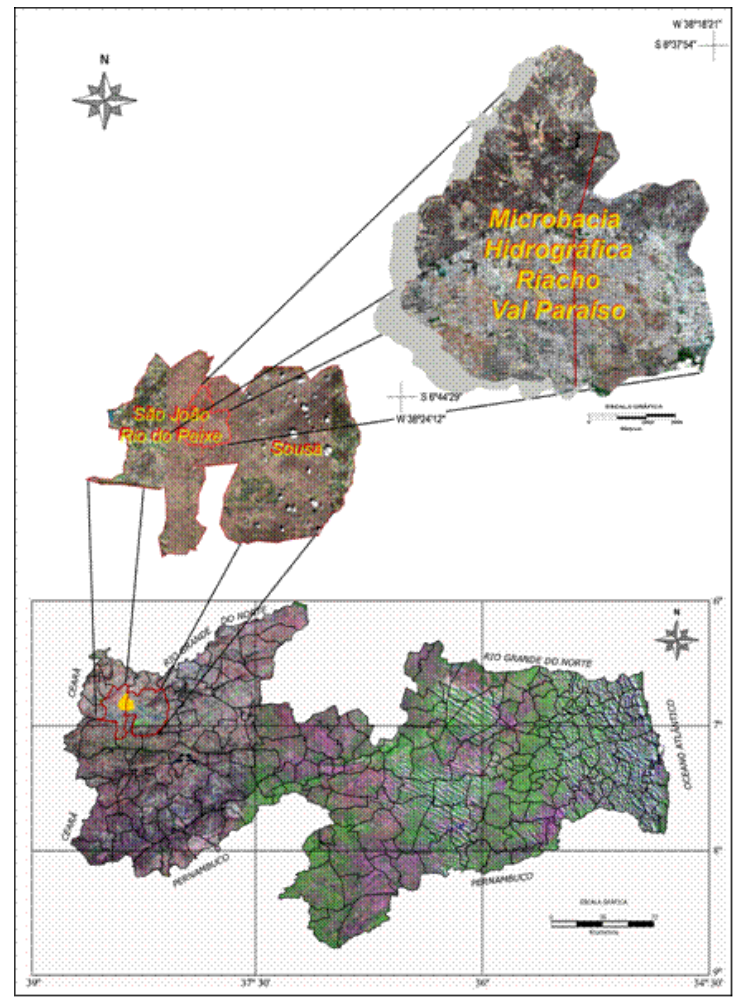

Figura 1- Localização microbacia hidrográfica riacho Val Paraíso. Fonte: Fernandes Neto (2009) 
A microbacia hidrográfica do Riacho Val Paraíso encontra-se geograficamente inserida na porção Noroeste do Estado da Paraíba, delimitada pelos paralelos de 6 $37^{\prime} 54^{\prime \prime}$ a $6^{\circ} 44^{\prime} 29^{\prime \prime}$ de latitude Sul e meridianos de $38^{\circ} 18^{\prime} 21^{\prime \prime}$ a $38^{\circ} 24^{\prime} 12^{\prime \prime}$ de longitude Oeste. Encontra-se entre os municípios de São João do Rio do Peixe e Sousa (Figura 1), distanciando-se aproximadamente 460 e $430 \mathrm{~km}$, respectivamente, da capital, João Pessoa.

A microbacia Val Paraíso apresenta uma área de 7.962,97 ha ou 79,63 $\mathrm{km}^{2}$, ou seja, uma área territorial maior que muitos municípios paraibanos. Dos $79,63 \mathrm{~km}^{2}$ de área da microbacia, $51 \%$ encontram-se inseridos no município de São João do Rio do Peixe e $49 \%$ no município de Sousa. Val Paraíso encontra-se na região do Alto Piranhas, dentro da sub-bacia hidrográfica do Rio do Peixe que por sua vez pertence à bacia hidrográfica do Rio Piranhas Açu. Esta bacia é considerada uma das mais importantes bacias hidrográficas dos estados nordestinos.

Na região onde se encontra a microbacia hidrográfica Val Paraíso, Semiárido paraibano, o clima dominante de acordo com Gaussen é do Tipo 4aTh, (tropical quente de seca acentuada) podendo atingir mais de $35^{\circ} \mathrm{C}$ em épocas de temperaturas mais elevadas, nos meses de setembro a novembro e temperaturas mais amenas, com valores pouco acima de $20^{\circ} \mathrm{C}$, entre os meses de maio a agosto. A vegetação é basicamente composta por Caatinga Hiperxerófila com trechos de Floresta Caducifólia. Quanto aos tipos de solos presentes na microbacia Val Paraíso, Fernandes Neto (2009) identificou predomínio da associação de Vertissolos e Planossolos Halomórficos.

A microbacia Val Paraíso abrange várias comunidades, como: a comunidade de Val Paraíso, Morumbira, Barracão, Fazenda Nova, Várzea da Jurema, Recanto, Fazenda do Padre, Sagui, Piau, Serrote Cabelo Não Tem, Baixio dos Albuquerques e Umburanas.

\subsection{Classificação da Pesquisa}

Para a classificação da pesquisa, tomou-se como base a metodologia adotada por Silva \& Nenezes (2001). Do ponto de vista da natureza a pesquisa é classificada como aplicada, em que se refere a conhecimentos para aplicação prática dirigidos à solução de problemas específicos. Quanto à forma de abordagem a pesquisa é classificada como quantitativa, a qual significa traduzir em números opiniões e informações para classificá-las e analisá-las. Do ponto de vista de seus objetivos a pesquisa pode ser classificada como exploratória, a qual envolve levantamento bibliográfico; entrevistas com pessoas que tiveram experiências práticas com o problema pesquisado; com relação aos procedimentos técnicos constituiu-se de um levantamento.

\subsection{Diagnóstico socioeconômico}

A metodologia de Rocha (1997), adaptada para o contexto do semiárido brasileiro por Sousa (2010) para levantar e analisar, em nível de identificação familiar, a situação social, econômica e tecnológica, consistiu em um questionário para ser aplicado junto aos agricultores da microbacia hidrográfica do Riacho Val Paraíso. Os fatores e variáveis analisados (Tabela 1) receberam notas de 1 a 10 conforme o grau de deterioração sendo que o maior e o menor escore representaram o maior e menor grau de deterioração, respectivamente. 
Tabela 1. Variáveis a serem pesquisadas

\begin{tabular}{c|l}
\hline Fator & \multicolumn{1}{c}{ Variáveis } \\
\hline Social & Demográfica; habitação; Participação em Organização (Associação) e salubridade rural. \\
\hline Econômico & $\begin{array}{l}\text { Produção; animais de trabalho; animais de produção; comercialização, crédito e } \\
\text { rendimento. }\end{array}$ \\
\hline Tecnológico & Tecnológica e maquinário e verticalização da produção (Industrialização Rural). \\
\hline
\end{tabular}

Os resultados foram avaliados e distribuídos obedecendo às recomendações de Rocha (1997) por meio da codificação dos indicadores, como segue:

Diagnóstico socioeconômico:

Total do fator social

Total do fator econômico

Total do fator tecnológico
Social + econômico + tecnológico

Do código 1.1 a 4.2

Do código 5.1 a 8.7

Do código 9.1 a 10.3

Estes códigos são os indicadores que foram utilizados para o cálculo da degradação de cada variável e fator.

Fez-se a tabulação dos dados agrupando-se os códigos de maior frequência e repetindo-os. Esta maior frequência se denomina "moda".

\subsection{Determinação do número de propriedades a serem visitadas}

O número de propriedades visitadas obedeceu à relação estipulada por Rocha (1997) que estabelece como ideal de visitação para a microbacia, o número de propriedades determinado pela expressão:

$$
n=\frac{3,841 X N X 0,25}{(0,1)^{2} X(N-1)+3,841 X 0,25}
$$

Em que:

n é número de visitas a serem realizadas pelo pesquisador;

3,841 é a constante do valor tabelado proveniente do Qui - quadrado;

0,25 é a variância máxima para o desvio padrão de 0,5 ;

0,1 é o erro (10\%) escolhido pelo pesquisador;

$\mathrm{N}$ é o número total de casa (moradias) na unidade considerada.

\subsection{Determinação da deterioração socioeconômica}

Para a tabulação dos dados foi atribuído códigos para cada item do questionário. Quanto maior for o número, maior a degradação do fator e, quanto menor o número, menor também será a degradação.

Na determinação da equação da reta $\mathrm{y}=a \mathrm{x}+b$, os coeficientes $a$ e $b$ foram calculados, por meio de um sistema de equação, da seguinte forma: 
$\mathrm{y}=a \mathrm{x}^{\prime}+b$, onde $\mathrm{y}=0 \%$ de deterioração, quando $\mathrm{x}^{\prime}=$ valor mínimo (valor mínimo $=1$ de cada ação proposta $\mathrm{x}$ número de ação, o que corresponde a 1 para a magnitude e a 1 para a importância do impacto);

$y=a x^{\prime \prime}+b$, onde $y=100 \%$ de deterioração, quando $x^{\prime \prime}=$ valor máximo (valor máximo $=10$ de cada ação proposta x número de ações, o que corresponde a 10 para a magnitude e a 10 para a importância do impacto).

Com os valores dos coeficientes $a$ e $b$ determinados, montou-se a equação da reta. Em seguida, os percentuais de deterioração $(y)$ foram calculados a partir da equação da reta por meio de substituição do valor significativo encontrado na região, ou seja, o valor da moda (x).

\section{RESULTADOS E DISCUSSÕES}

Os valores agravantes, no diagnóstico social, são decorrentes dos elevados valores modais encontrados para os indicadores que compõem a variável demográfica e habitação, mais especificamente, idade do chefe de família, grau de instrução do chefe de família, média de idade do núcleo familiar e eliminação de lixos que apresentaram moda de valores indesejáveis, ou seja, valor máximo para a moda (10). Tendendo a valores altos, encontra-se o indicador participação em organização (variável associação), infestação de pragas (variável salubridade rural) apresentando valor modal igual a 7 , e combate a pragas (variável salubridade rural) que apresentou valor modal 5. Outro resultado relevante está relacionado ao número de pessoas que compõe a família, neste sentido, verificou-se que $30 \%$ das famílias pesquisadas são compostas por uma a duas pessoas, reduzindo assim a força de trabalho, fenômeno característico do êxodo rural.

A variação dos valores (máximo, mínimo e moda) encontrados na área estudada com ênfase para o fator social, o que engloba as variáveis demográfica, habitação, organização da comunidade e salubridade é apresentada na Figura 2. Observa-se nesta figura que as variáveis demográfica, salubridade e organizacional apresentam o valor modal próximo ao valor máximo atribuído, o que consequentemente contribuirá para o aumento do índice de deterioração social, corroborando Franco et al. (2005).

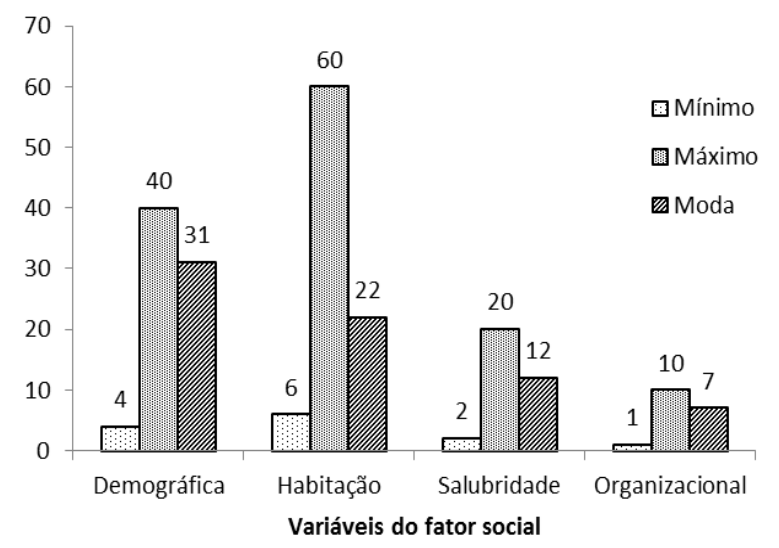

Figura 2 - Valores de máximo, mínimo e moda para as variáveis do fator social

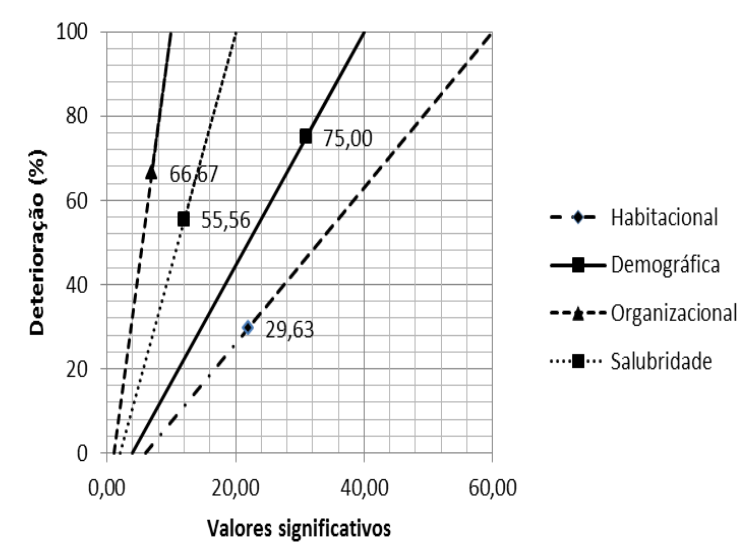

Figura 3 - Deterioração para cada variável do fator social 
De acordo com a Figura 3, a reta da variável habitacional apresentou a menor inclinação, o que implica dizer que qualquer que seja a variação do valor significativo haverá uma pequena variação na deterioração; por outro lado a reta da variável organizacional indicou maior inclinação tendo em vista que apenas uma variável foi analisada, ou seja, uma variação menor no valor significativo implica em uma variação maior na deterioração.

A variável habitação apresentou o menor valor da deterioração (29,63\%) para o fator social, semelhante ao valor encontrado por Ferreira et al. (2008). Os indicadores que contribuíram para que a variável habitação apresentasse a menor deterioração, ao ser comparada com as outras variáveis do fator social, foi o tipo de habitação uma vez que a maior parte das pessoas pesquisadas reside em casa de alvenaria boa e utilizam água potável para o consumo familiar. A variável demográfica apresentou a maior deterioração (75\%) entre as variáveis do fator social, valor superior ao encontrado por Baracuhy (2001) que verificou uma deterioração demográfica na ordem de $39,81 \%$ para a microbacia do riacho Paus-Brancos. Na presente pesquisa os indicadores que mais contribuíram para esse alto valor de deterioração foi a idade e o grau de instrução do chefe da família e a média de idade do núcleo familiar.

As variáveis salubridade e organizacional também apresentaram altos índices de deterioração 55,56 e $66,67 \%$, respectivamente. Os valores da salubridade foram inferiores aos encontrados por Franco et al. (2005) que ao avaliar os fatores de risco da deterioração ambiental ocasionada pela exploração agropecuária e extrativismo vegetal, verificou-se uma deterioração de 100\% para esta variável. Abreu et al. (2011) com o objetivo de determinar o grau de deterioração social da microbacia hidrográfica Riacho da Igreja, identificaram o índice de deterioração de $100 \%$ e 40,74 \% para as variáveis de organização social e salubridade.

A variável demográfica, organizacional e salubridade foram as que mais contribuíram para o alto índice de deterioração social (50,43\%), corroborando Alves \& Alves (2012). Este índice encontrado indica que mais da metade da área social se acha deteriorada; a deterioração, 50,43 $\%$, encontra-se muito acima do valor aceitável estipulado por Rocha (1997) que segundo sua metodologia o valor tolerável para a deterioração é $10 \%$.

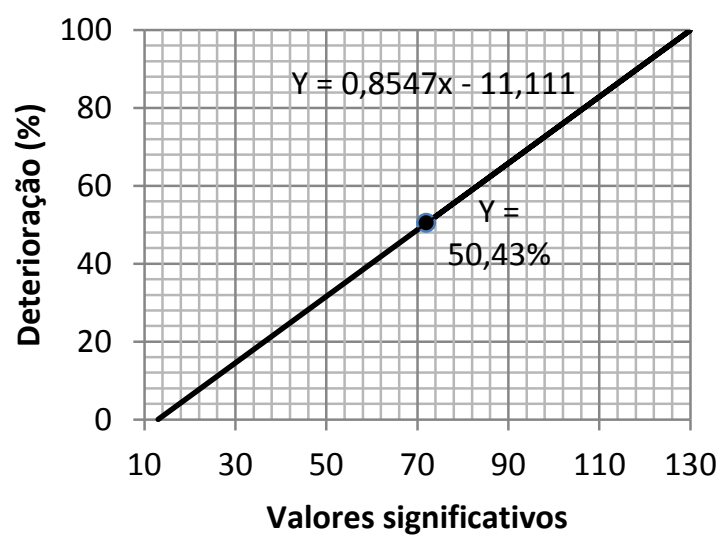

Figura 4 - Deterioração do fator social

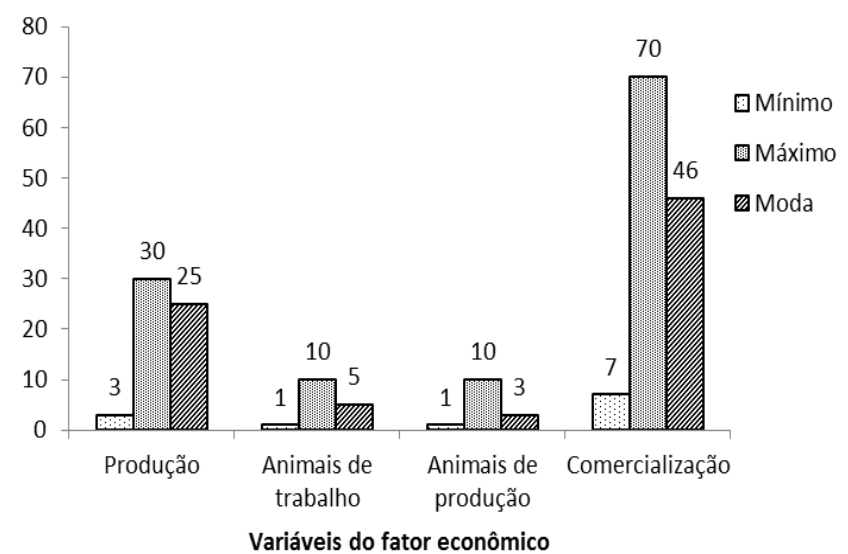

Figura 5 - Valores de máximo, mínimo e moda para as variáveis do fator econômico 
Ao avaliar a situação socioeconômica da microbacia do Riacho da Serra, Ferreira et al. (2008) identificaram uma deterioração social de 30,98 \%, sendo que a principal variável que contribuiu para este índice foi o diagnóstico alimentar.

As variáveis produção, animais de trabalho e comercialização apresentaram os valores modais próximos dos valores máximos atribuídos, contribuindo assim para uma elevada deterioração econômica da área estudada (Figura 5).

Como pode ser visto na Figura 6 as variáveis que apresentaram maior deterioração foram a produção e comercialização crédito e rendimento, com os valores de $81,48 \%$ e $61,90 \%$, respectivamente.

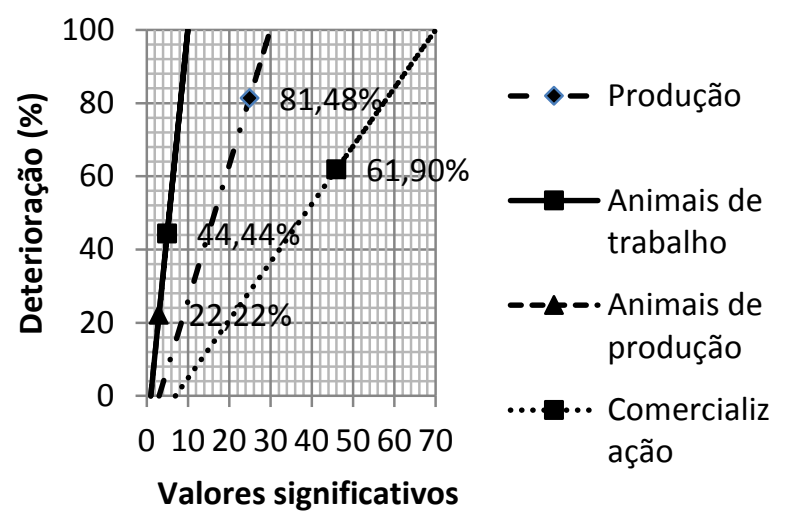

Figura 6 - Deterioração para o fator econômico

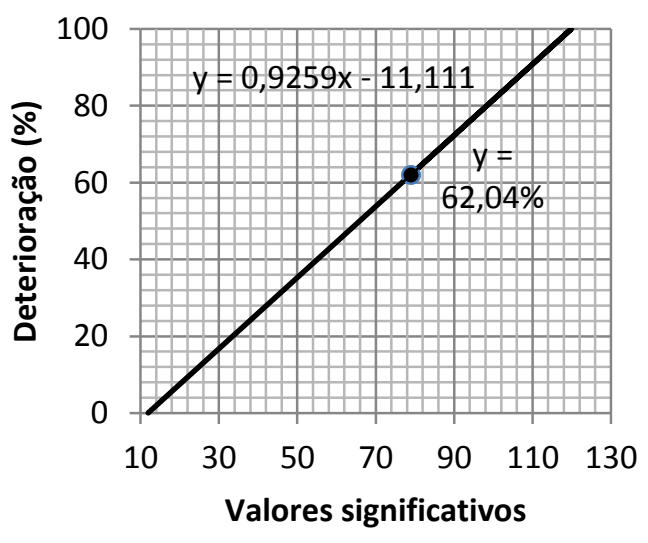

Figura 7 - Deterioração do fator econômico

O diagnóstico econômico apresentou valores agravantes decorrentes da falta de florestamento e manutenção da vegetação nativa (variável produção); na região o florestamento nas propriedades está abaixo de $1 \%$ e os produtores não possuem pastagens plantadas; os produtores não vendem a produção agrícola e florestal (variável comercialização, crédito e rendimento) o que gerou valor de moda muito elevado (valor 10). A renda da propriedade (variável comercialização, crédito e rendimento) apresentou valor modal elevado (valor 9), e a renda total apresentou moda igual a 7 o que está relacionada, diretamente, ao incremento financeiro proporcionado por outras fontes de renda, mais especificamente, bolsa família e aposentadorias.

Os indicadores que mais contribuíram para os valores elevados da deterioração produção foram florestamento e pastagem plantada. Com relação a variável comercialização, crédito e rendimento os itens que mais contribuíram para o alto índice de deterioração foi o fato da população não vender a produção agrícola, florestal e a propriedade ter apresentado no ano de 2012 uma renda inferior a um salário mínimo mensal.

Para o fator econômico a variável animal de produção apresentou o menor índice de deterioração; isso ocorre devido ao fato de que a maioria da população residente na microbacia possui no mínimo três tipos de animais de produção. Já em relação aos animais de trabalho verificou-se que a maioria da população possui apenas um animal de trabalho.

As variáveis produção e comercialização crédito e rendimento foram as que mais contribuíram para o alto índice de deterioração econômica $(62,04 \%)$ indicando que mais da 
metade do fator econômico se acha deteriorado. Este valor encontra-se muito acima de $10 \%$, valor máximo tolerável conforme Rocha (1997).

O índice de deterioração econômica foi inferior ao encontrado por Franco et al. (2005), que encontraram uma deterioração econômica na ordem de 80 \%. Verifica-se que a deterioração econômica (63,33\%) encontrada por Ferreira et al. (2008) é semelhante ao índice de deterioração encontrados na presente pesquisa.

Os valores significativos encontrados na área estudada com ênfase para o fator tecnológico, o que engloba as variáveis tecnologia e industrialização rural são apresentados na Figura 8. Observa-se que o valor modal da variável industrialização rural, do fator tecnológico, ficou próximo ao valor máximo atribuído, indicando com isto, que esta variável apresentou índice de deterioração maior do que a variável tecnológica.

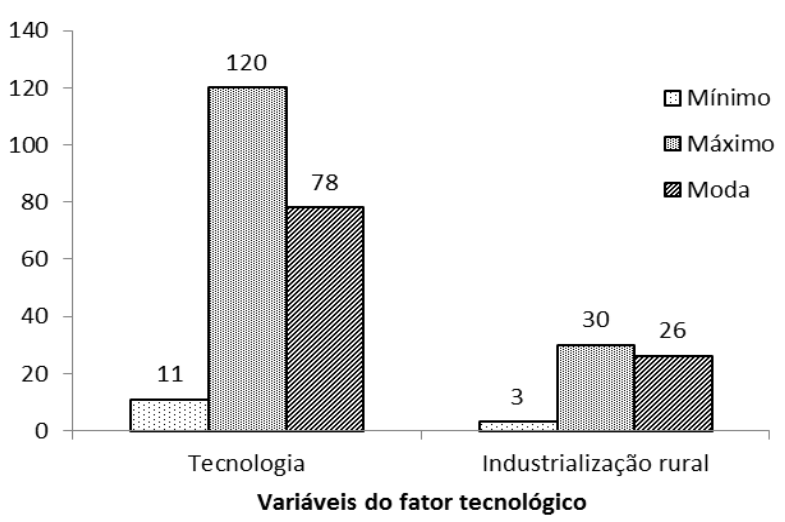

Figura 8 - Identificação do diagnóstico socioeconômico: fator tecnológico

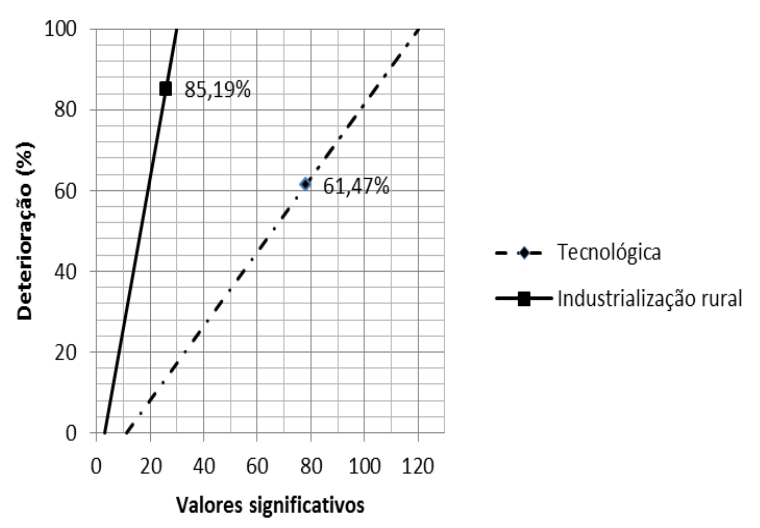

Figura 9 - Deterioração para cada variável do fator tecnológico

A Figura 9 apresenta as deteriorações 61,47 e 85,19 \% para a variável tecnológica e industrialização rural. Observa-se valores elevados de deterioração para as duas variáveis, o que contribui para que a deterioração tecnológica apresente o índice mais elevado em comparação com as deteriorações sociais e econômicas anteriormente apresentadas.

As situações que mais contribuíram para a elevada deterioração tecnológica foi o fato de que a maior parte da população pesquisada não usa nenhum tipo de adubação do solo, possui apenas ferramentas manuais para o trabalho agrícola, não faz uso de irrigação e não possui assistência técnica. Já em relação a variável maquinário e verticalização da produção, os itens que mais contribuíram para o elevado índice de deterioração foram: a ausência de atividades complementares de renda a exemplo do desenvolvimento de algum tipo de artesanato e também por não agregarem valores com o processamento da matéria prima utilizada na propriedade.

O índice de deterioração tecnológica, 66,18\% (acima do valor máximo aceitável, 10\%) indica que mais da metade da área tecnológica se acha deteriorada (Figura 10). 


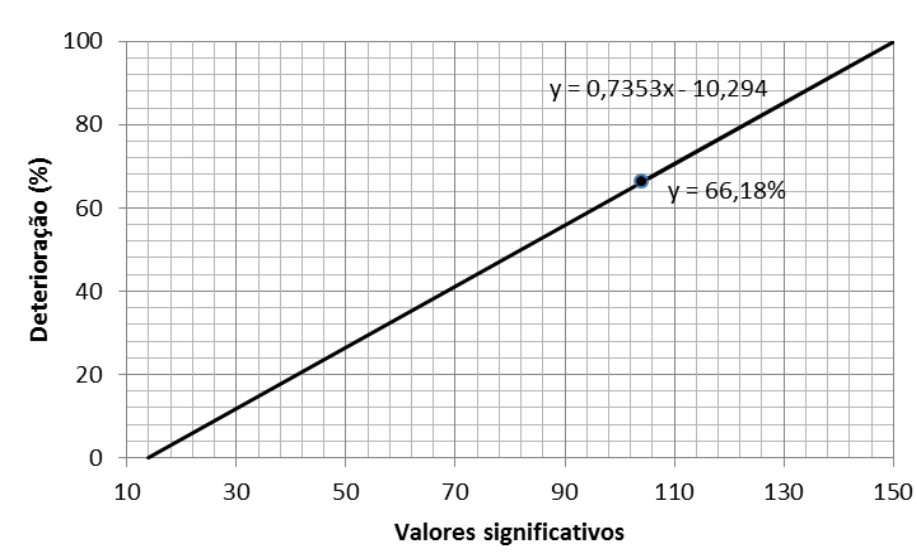

Figura 10 - Deterioração do fator tecnológica

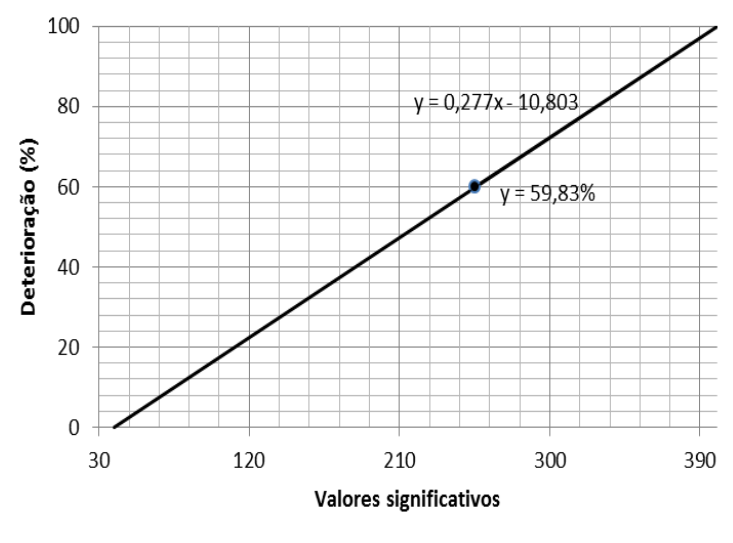

Figura 11 - Deterioração do fator socioeconômico

Ao investigarem a deterioração socioeconômica de assentamentos rurais no Estado da Paraíba, Alves \& Alves (2012), verificaram uma deterioração tecnológica de $78,21 \%$. Com o objetivo de avaliar a deterioração socioeconômica e ambiental na microbacia do Riacho Poço da Serra, localizada em um núcleo de desertificação no Seridó Potiguar, Silva \& Mattos (2013) identificaram uma deterioração tecnológica $82,30 \%$. Pereira \& Barbosa (2009) ao investigarem a microbacia hidrográfica Serrote Cabelo Não Têm em São João do Rio do Peixe identificaram uma deterioração tecnologia de $64,42 \%$.

Observa-se na Figura 11 um elevado índice de deterioração socioeconômica (59,83\%) na microbacia hidrográfica do Riacho Val Paraíso - PB; o respectivo valor está acima do valor máximo aceitável (10\%), conforme Rocha (1997). Esse índice de deterioração socioeconômica indica que a população da respectiva microbacia, segundo os padrões da metodologia utilizada, se encontra em precárias condições socioeconômicas, corroborando com Alves \& Alves (2012) que encontraram índice semelhante de deterioração socioeconômica (55,58\%) ao investigaram assentamentos rurais no Estado da Paraíba.

O índice de deterioração socioeconômica encontrado na presente pesquisa foi muito superior a deterioração diagnosticada por Ferreira et al. (2008) que ao realizaram um estudo da deterioração socioeconômica na microbacia do Riacho da Serra, PB identificaram uma deterioração de 37,96\%. Silva \& Mattos (2013) identificaram uma deterioração socioeconômica na ordem de $41,00 \%$.

\section{CONCLUSÕES}

Na avaliação da deterioração socioeconômica da microbacia do Riacho Val Paraíso - PB constatou-se que a região encontra-se em elevado processo de deterioração socioeconômica, com mais de $50 \%$ da área comprometida. Os resultados encontrados indicam que para todos os fatores estudados haverá a necessidade da intervenção do poder público e/ou sociedade organizada para que de forma articulada possam empregar ações direcionadas para solução dos problemas identificados de forma mais agravante.

As comunidades pesquisadas estão vulneráveis às condições adversas do semiárido do nordeste brasileiro. Os valores das deteriorações calculadas, por meio do sistema de atribuição de pesos às variáveis, foram elevados em relação ao valor máximo atribuído (10\%) de acordo com a 
metodologia empregada. $O$ índice de deterioração social foi inferior em relação aos demais fatores. Os atenuantes do grau de deterioração social estão relacionados aos programas sociais promovidos pelo Governo Federal, que melhoraram a renda familiar, no entanto, os altos valores ainda mostram o grau de pobreza da população do campo, sua insegurança e suas dificuldades de, por si só, fazer mudanças significativas, visando um desenvolvimento sustentável.

\section{REFERÊNCIAS}

1. ARAUJO, K. D. Análise da vegetação e organismos edáficos em áreas de caatinga sob pastejo e aspectos socioeconômicos e ambientais de São João do Cariri - PB, 2010. 166f Tese (Doutorado em Recursos Naturais) - Universidade Federal de Campina Grande, Campina Grande - PB, 2010.

2. ABREU, B. S. de; FERNANDES NETO, S.; MELO, A. A. de; MELO, G. K. R. M. M. de; LIMA, P. C. da S.; MORAIS, P. S. de A.; OLIVEIRA, Z. M. de. Diagnóstico socioeconômico da microbacia hidrográfica do Riacho da Igreja, Cabaceiras/PB. Revista Educação Agrícola Superior, v. 26, n. 1, p. 25-29, 2011.

3. ALVES, A. R.; ALVES, J. B. Riscos e vulnerabilidades em assentamentos rurais no Estado da Paraíba. Revista Geonorte, v. 2, n. 5, p. 112-1132, 2012.

4. ALVES, T. L. B.; AZEVEDO, P. V. de; FARIAS, A. A. de. Diagnóstico socioambiental do entorno da microbacia hidrográfica do Riacho Namorado no Município de São João do Cariri - PB. Ateliê Geográfico, v.6, n.4, p. 88-109, 2012.

5. BARACUHY, J. G. V. Manejo integrado de micro bacias no Semi-árido nordestino: estudo de caso, 2001. 221f. Tese (Doutorado em Recursos Naturais) - Universidade Federal da Paraíba, Campina Grande - PB,2001.

6. BARRETO, H. F. M. Impacto do manejo agroecológico da caatinga em unidaes de produção familiar no Oeste Potiguar,2010. 143f. Dissertação (Mestrado em Ciência Animal) Universidade Federal Rural do Semiárido, Mossoró - RN, 2010.

7. BARROS, J. D. S.; SILVA, M. F. P. Práticas agrícolas sustentáveis como alternativas ao modelo hegemônico de produção agrícola.Sociedade e Desenvolvimento Rural, v.4, n. 2, p. 89-103, 2010.

8. CAMELHO, G. L. P.; CÂNDIDO, G. A. Potencialidades e limitações dos agroecossistemas familiares de cultivo do abacaxi em Touros (RN). Holos, v. 6, n. 6, p. 3-27, 2012.

9. FERNANDES NETO, S. Planejamento do uso racional dos recursos naturais da microbacia hidrográfica do riacho Val Paraíso - PB, através de mapeamento geoambiental. 2009. 117f. Dissertação (Mestrado em Recursos Naturais). Campina Grande - PB, 2009.

10. FERREIRA, C. A.; TRAVASSOS, K. D.; LOPES, R. M. B. P.; FORMIGA, M. do S.; FARIAS, S. A. R.; BARACUHY, J. G. de V.; SILVA, M. B. R. Diagnóstico socioeconômico do município de São José do Sabugi, PB. Revista educação Agrícola Superior, v. 23, n. 1, p. 101-104, 2008.

11. FRANCO, E. S.; LIRA, V. M.; PORDEUS, R. V.; LIMA, V. L. A. de; DANTAS NETO, J. D.; AZEVEDO, C. A. V. DE. Diagnóstico socioeconômico e ambiental de uma microbacia no Município de Boqueirão - PB. Engenharia Ambiental, v. 2, n. 1, p. 100-114, 2005.

12. LIRA, R. B. de. Qualidade do solo e avaliação econômica do manejo sustentável da caatinga no 
projeto de assentamento Moacir Lucena, Apodi, RN. 2010. 64f. Dissertação (Mestrado em Ciência do Solo) - Universidade Federal Rural do Semiárido, Mossoró - RN, 2010.

13. PEREIRA, R. A.; BARBOSA, M. de F. N. Diagnóstico socioeconômico e ambiental de uma microbacia hidrográfica no semiárido paraibano. Engenharia Ambiental, v. 6, n. 1, p. 137-153, 2009.

14. REIS, L. M. M.; CÂNDIDO, G. A. Sustentabilidade dos agroecossistemas intensivos de bananeira de Ipanguaçu-RN. Holos, v.6, n.6, p. 28-42, 2012.

15. ROCHA, J. S. M. da.Manual de projetos ambientais. Santa Maria: UFSM, 1997. 423p.

16. ROCHA, J. S. M. da; KURTZ, S. M. de J. M. Manual de manejo integrado de bacias hidrográficas. Santa Maria: Edições UFSM CCR/UFSM, 2001. 302p.

17. SÁ, I. B.; CUNHA, T. J. F.; TEIXEIRA, A. H. de C.; ANGELOTTI, F.; DRUMOND, M. A. Processo de desertificação no Semiárido brasileiro. In: SÁ, I. B.; SILVA, P. C. G. da. Semiárido brasileiro. Petrolina, PE: Embrapa Semi-Árido, p. 126-158, 2010.

18. SÁ, V. C.; SOUZA, B. I. Convivência com o semiárido: Desafios e possibilidades de uma comunidade rural. Revista de Globalizacion, Competitividad y Gobernabilidad, v. 6, n. 2, p. 4665, 2012.

19. SILVA, E. L. da; MENEZES, E. M. Metodologia da pesquisa e elaboração de dissertação. Florianópolis: Laboratório de Ensino a Distância da UFSC, 2001. 121p.

20. SILVA, D. D. C.; MATTOS, A. Diagnóstico socioeconômico e ambiental em microbacia hidrográfica localizada em um núcleo de desertificação. Caminhos de Geografia, v. 14, n. 45, p. 45-53, 2013.

21. SILVA, P. C. G. et al. Caracterização do semiárido brasileiro: fatores naturais e humanos. In: SÁ, I. B.; SILVA, P. C. G. Semiárido Brasileiro. Petrolina, PE: Embrapa Semi-Árido, p. 17-48, 2010.

22. SOUSA, R. F. de; BARBOSA, M. P.; MORAIS NETO, J. M. de; MENESES, L. F. de; GADELHA, A. G. Vulnerabilidades e impactos socioeconômicos e ambientais em municípios do Cariri paraibano. Engenharia Ambiental, v. 5, n.3, p. 63-78, 2008.

23. SOUSA,V. G. de. Diagnóstico e prognóstico socioeconômico e ambiental das nascentes do Riacho das Piabas (PB). 2012. 108f. Dissertação (Mestrado em Recursos Naturais) Universidade Federal de Campina Grande. Campina Grande - PB, 2010. 